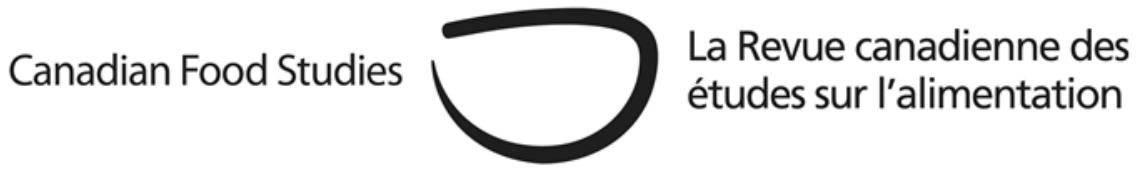

Book Review

\title{
Indigenous food systems: Concepts, cases and conversations
}

\author{
Priscilla Settee and Shailesh Shukla (Eds) \\ Canadian Scholars' Press, 2020, 284 pages
}

\section{Review by Kristen Lowitt ${ }^{*}$}

Food was a fundamental tool of colonization, used to oppress and dispossess Indigenous peoples from their cultures, knowledge, and land. However, food can also be a powerful tool for reconciliation. Food has become a critical site of decolonial struggle as seen in the efforts of Indigenous people around the globe to reclaim their food systems and establish ways of harvesting, producing, and preparing food that nourish both people and the land. The edited collection Indigenous Food Systems: Concepts, Cases and Conversations by Priscilla Settee and Shailesh Shukla explores these issues focusing on Turtle Island (North America).

With contributions from Indigenous scholars, communities, and non-Indigenous allies, a compelling attribute of this book is that it demonstrates Indigenous food systems in action. Through numerous case studies and rich descriptions of place-based food practices, the book celebrates Indigenous food systems and the diverse cultures and knowledge systems they are based in. The text recognizes that reconciliation is not just about righting past wrongs or about establishing respectful Indigenous-settler relationships but is about the active resurgence of Indigenous cultures and identities as enacted through food. The book is targeted towards upperlevel undergraduate and graduate level students, with each chapter containing a useful set of learning objectives, key terms, suggested reading and resources, and discussion questions. However, the book's broad engagement with food systems theory and empirical case studies will make it appealing to food studies practitioners and scholars as well.

The collection begins with an introductory chapter that presents the key terms used in the book, including food security, food sovereignty, Indigenous food sovereignty, and Indigenous foods, and provides a brief overview of the collection. The accessibly written and succinct

\footnotetext{
*Corresponding author: lowitt@brandonu.ca DOI: $10.15353 /$ cfs-rcea.v7i1.411

ISSN: 2292-3071
} 
description of key terms in this first chapter promises to make it a helpful reference guide for students. The collection then proceeds in three parts: concepts, cases, and conversations.

The first section, Chapters 2-5, elaborates concepts important to understanding Indigenous food systems. In Chapter 2, Dawn Morrison describes how a capitalist and production-oriented agricultural paradigm has made Indigenous food systems invisible. She stresses the importance of renewing Indigenous food sovereignty based in principles of selfdetermination, the sacredness of food, participation in land-based activities, and policy. It is appropriate that this chapter is placed early in the book since the theory and practice of Indigenous food sovereignty, described in detail by Morrison, lays the basis for the chapters that follow. In Chapter 3, Elisa Levi demonstrates a strength-based approach to food security by documenting the practices used to maintain food security at individual, family, and community levels in the community of Elsipogtog First Nation. In Chapter 4, Agnieszka PawlowskaMainville identities the unique features of Anishinaabe food systems in the boreal forest using Poplar River First Nation as a case study. In Chapter 5, Leslie Dawson applies critical discourse analysis to look at how colonialism and the Eurocentric foodway operates in Canada's Food Guide.

The second section of the book, chapters 6-10, features community-based case studies. While providing practical examples of Indigenous food systems the authors also share considerable methodological detail that illuminates the process of partnership-driven Indigenous research. Erynne M. Gilpin and Mary Hayes in Chapter 6 describe land-based food and education as entryways into establishing Indigenous food system governance, drawing on the experiences of the W-JOLELP Tsartlip First Nation Garden Project. Chapter 7 presents Asfia Gulrukh Kamal's case study of the O-Pipon-Na-Piwin Cree Nation's intergenerational community-based food program based in oral storytelling traditions. Chapters 8 and 10 focus on urban settings, with Tabitha Robin (Martens) and Jaime Cidro (Chapter 8) looking at access to traditional foods in Winnipeg's inner city. Chapter 9 by Hara Nikolopoulos, Anna Farmer, David Dyck Fehderau, Joanna Campiou, and Noreen Willows describes a workshop series developed to support community capacity to form a food policy council in Alexander First Nation in Alberta. In Chapter 10, Lise Kouri, Rachel Engler-Stringer, Tenille Thomson, and Melody Wood explore the food practices of urban Indigenous households and share the experiences of the Good Food Junction in Saskatoon in trying to support Indigenous food sovereignty in an urban environment.

The final section of the book, chapters 11-15, offers commentaries on contemporary issues that crosscut many of the chapters in the book. In Chapter 11, Shirley Thompson and Pepper Pritty look at how modern development and the destruction of land impedes food security in northern and remote communities drawing on the case of the O-Pipon-Na-Piwin Cree Nation. In Chapter 12, Priscilla Settee reviews the impacts of climate change on Indigenous food systems and the importance of Indigenous knowledge in mitigating climate change. In Chapter 13, Brielle Beaudin-Reimer looks at Métis perspectives and contributions to the social, economic, legal, and political history of Indigenous food systems in Manitoba. In Chapter 14, Hannah Tait Neufeld shares the food experiences of Elder Indigenous women living on and off reserve considering the 
impacts of environmental dispossession, residential schools, the wage economy, and urbanization. The final chapter in this section is a thorough synthesis by the editors that ties together the various chapters of the book through an analysis of the unique features, challenges to, and strategies for supporting Indigenous food systems.

One thing I would have liked to have seen is an expanded introductory chapter by the editors laying out the context for the collection, including a history of colonialism in Canada, Treaty relationships, and discussion of reconciliation. Much of this is covered to varying degrees by the authors within their respective chapters; however, a more comprehensive introductory chapter could have reduced repetition in background material across chapters while further setting the scene for the chapters that follow.

Overall, this text is a timely addition to teaching and scholarship on Indigenous food systems. It contains numerous pedagogical features that will make it easy to use in the classroom. At the same time, it is an important contribution to collaborating with Indigenous peoples and their food systems in support of maintaining and reviving not only food systems but the sovereignty of Indigenous nations themselves. As the editors point out, "Indigenous Peoples must be food sovereign in order to be sovereign as a Nation" (pg.1).

\section{Kristen Lowitt is Assistant Professor in the School of Environmental Studies at Queen's} University. Her research is directed towards working with communities to build just and sustainable food systems. Interests include the role of fisheries in sustainable food systems, Indigenous food sovereignty, and collective action in food systems governance. 